\title{
Correlação entre a Inflação e a Exportação de carne bovina no Brasil de 2000 a 2015
}

Correlation Between Inflation and Beef Exports in Brazil 2000-2015

Corrélation entre l'inflation et l'exportation de la viande bovine au Brésil

2000-2015

Correlación entra la inflación ey la exportación de Carne Bovina en Brasil de 2000 a 2015.

Denis Fernandes Alves, Pedro José Rebouças Filho e Paulo Victor Maciel da Costa

\section{(2) OpenEdition}

Journals

\section{Edição electrónica}

URL: http://journals.openedition.org/espacoeconomia/4661

DOI: 10.4000/espacoeconomia.4661

ISSN: $2317-7837$

\section{Editora}

Núcleo de Pesquisa Espaço \& Economia

\section{Refêrencia eletrónica}

Denis Fernandes Alves, Pedro José Rebouças Filho e Paulo Victor Maciel da Costa, « Correlação entre a Inflação e a Exportação de carne bovina no Brasil de 2000 a 2015 », Espaço e Economia [Online], 13 | 2018, posto online no dia 16 dezembro 2018, consultado o 02 maio 2019. URL : http:// journals.openedition.org/espacoeconomia/4661 ; DOI : 10.4000/espacoeconomia.4661 


\section{Correlação entre a Inflação e a Exportação de carne bovina no Brasil de 2000 a 2015}

Correlation Between Inflation and Beef Exports in Brazil 2000-2015

Corrélation entre l'inflation et l'exportation de la viande bovine au Brésil

2000-2015

Correlación entra la inflación ey la exportación de Carne Bovina en Brasil de

2000 a 2015.

Denis Fernandes Alves, Pedro José Rebouças Filho e Paulo Victor Maciel da Costa

\section{Introdução}

1 Desde o início da colonização do Brasil o gado se mostrou muito importante para o desenvolvimento nacional. Passando por vários processos de expansão, a pecuária figura atualmente como um dos principais setores da economia nacional, com grande geração de emprego e renda (Ministério da Agricultura, Pecuária e Abastecimento - MAPA, 2007).

A conjuntura econômica mundial nos anos de 1990 favoreceu a criação de gado e, no Brasil, a abertura comercial e a queda nas taxas de inflação reforçaram ainda mais os motivos para o dinamismo apresentado pela pecuária, ao longo do tempo, na economia brasileira (ABREU; HERRA; TEIXEIRA, 2006 e SOUSA, 2008).

Paralelamente à atividade açucareira no Brasil desenvolvia-se a pecuária a qual se expandia pela facilidade de aumento do rebanho e incorporação de baixa quantidade de mão de obra. Mão de obra esta que na economia açucareira era mais significativa. A economia criatória nordestina, no entanto, era inviável para aqueles que se localizavam distante do litoral, ademais o grau de especialização e de comercialização, garantia-lhe baixa produtividade, em relação a sua dependente. Essa atividade era encarada como de subsistência e tinha matéria-prima o couro que servia para quase tudo (FURTADO, 2005). 
4 A carne bovina era um bem fundamental para a colônia, pois era destinada à satisfação das necessidades alimentares da população, mas apesar da importância relativa da atividade, a pecuária figurava-se como um setor de subsistência e acessório da economia açucareira. A cultura de cana de açúcar não permitia a criação de gado nas terras férteis do litoral, em virtude disso, a atividade se desenvolveu no interior brasileiro, em especial no sertão nordestino, com condições pluviométrica, vegetativa e de qualidade ínfimas. No entanto, apesar das desvantagens, a criação de gado se dispersou rapidamente pela região, se alastrando principalmente nos estados da Bahia e do Pernambuco. A rápida dispersão da atividade no Nordeste, pode ser explicada pelo consumo crescente do litoral onde se desenvolvia a economia açucareira, mas também pelo baixo grau de monetização, densidade econômica e produtividade da indústria. Quanto ao abastecimento dos núcleos da porção meridional do Brasil, desenvolveram-se outras regiões criatórias de gado, com condições naturais superiores às condições naturais nordestinas, cujo gado se desenvolvia com melhor qualidade. No entanto, as fazendas de criação não se espalharam tanto como na região Nordeste. (PRADO JUNIOR, 1981).

5 Nesse contexto, a pecuária era vista, em seu processo embrionário, como uma atividade especulativa, demarcação territorial e de subsistência. Paulatinamente a pecuária foi conseguindo importância na pauta de exportação. Essa iniciativa foi decorrente da concorrência entre a carne bovina e a de frango, bem como das importações, que incentivou o melhoramento técnico da produção de carnes. Ademais, outros fatores corroboram a dinâmica desta atividade tanto no mercado interno quanto no externo, como a taxa de câmbio, fator preponderante na exportação de carnes, já que a oscilação dessa taxa pode causar impactos significativos na competitividade brasileira no mercado internacional, tendo em vista que irá causar efeitos nos preços dos produtos (ISAAC, 2006).

6 Desse modo, o presente estudo busca analisar a correlação entre a exportação de carne bovina e a inflação no Brasil de 2000 a 2015. Além disso, foi feita uma revisão literária sobre a pecuária e sobre a inflação no Brasil. Para atender ao objetivo proposto, utilizouse dados secundários da AliceWeb, IPEADATA e Banco Central do Brasil.

7 O trabalho encontra-se estruturado em 4 partes além desta introdução. A segunda seção é referente à bibliografia sobre a pecuária e sobre a inflação no Brasil e a terceira traz as notas metodológicas, enquanto a quarta trata da análise da correlação entre exportação de carne bovina e inflação no país de 2000 a 2015. Por fim, são apresentadas as conclusões do estudo.

\section{Contextualização da pecuária e da inflação no B rasil}

\subsection{Pecuária}

8 Segundo o Ministério da Agricultura, Pecuária e Abastecimento (2007, p. 19), "a cadeia de carne bovina ocupa posição de destaque no contexto da economia rural brasileira, ocupando vasta área do território nacional e respondendo pela geração de emprego e renda de milhões de brasileiros". "Em 2003, segundo o Instituto Brasileiro de Geografia e Estatística (IBGE), a agropecuária empregou cerca de 17,6 milhões de pessoas, ou seja, $24,2 \%$ da População Economicamente Ativa (PEA) " (ISAAC, 2006). 
O primeiro rebanho chegou ao país no século XVI e inicialmente era utilizado em atividades de subsistência. A força bruta do animal era utilizada para transportar cargas, a carne era utilizada na alimentação e o couro na produção de assessórios. A partir do século XIX, com a chegada da espécie Zebuína, que se adaptava melhor ao clima e ao pasto brasileiro, principalmente nas regiões sudeste e centro-oeste, houve um forte aumento na quantidade de rebanhos e o país se destaca como grande produtor de gado comercial mundial. No século XX houve muito incentivo na pecuária, inclusive financeiro, nas regiões Norte e Centro-Oeste o que causou forte valorização e expansão dessas regiões (ABREU; HERRA; e TEIXEIRA, 2006).

Nos anos de 1990 foi onde se teve um aumento mais expressivo da criação de gado no Brasil, alcançado o segundo maior rebanho do mundo, ficando atrás apenas do da Índia. Nesta época, a comercialização da carne bovina no mercado mundial foi favorecida pela conjuntura econômica, que estava passando por um processo de abertura comercial nos Governos de Collor e Fernando Henrique Cardoso (ABREU; HERRA; e TEIXEIRA, 2006).

\begin{abstract}
A derrubada das altas taxas inflacionárias impostas pelo "Plano Real", a partir de 1994, deu início às grandes modificações no setor primário brasileiro, particularmente na atividade pecuária, que por muito tempo obteve seus lucros pela elevada desvalorização da moeda. Esse novo momento exigiu que as propriedades rurais se tornassem empresas eficientes, o que fez com que os índices produtivos se elevassem consideravelmente. Não se pode perder de vista que, mesmo as pequenas modificações em índices produtivos, representam um acréscimo considerável de animais e carne no mercado, em consequência do tamanho do rebanho brasileiro (SOUZA, 2008, p. 429).
\end{abstract}

11 Na década de 2000 foi quando o Brasil alcançou seus maiores resultados na produção e exportação do produto. Se tornando o segundo maior produtor mundial de carne bovina, ficando atrás dos Estados Unidos, o maior exportador mundial. Quando, $1 \mathrm{em}$ cada 5 quilos de carne bovina comercializada no mundo era de origem brasileira (ABREU; HERRA; e TEIXEIRA, 2006).

12 A grande produção nacional é favorecida pela extensão territorial e pelo clima que favorece o cultivo de pastos, sendo que todas as regiões comportam produtores bovinos, tendo destaque às regiões Sudeste e Centro-Oeste. De uma forma geral, a indústria frigorífica nacional possui um alto nível tecnológico e grande competitividade no mercado mundial. Tem-se investido muito no desenvolvimento de técnicas inovadoras e em evolução genética, fazendo com que se tenha uma maior qualidade no produto final (ABREU; HERRA; e TEIXEIRA, 2006).

13 Porém a exportação ainda esbarra em barreiras tarifárias e não tarifárias. A questão sanitária e questões éticas são os argumentos que mais frequentemente são utilizados pelos países compradores para barrar a carne bovina brasileira. Quanto aos fatores sanitários, é comum que os países que importam o produto brasileiro visitem a produção da carne e avaliem se o processo se adequa às suas especificações, onde acontece de muitas empresas serem barradas por não corresponderem às regras impostas. $O$ controle de doenças no gado - como a febre aftosa que ainda não conseguiu ser erradicada no país - os cuidados com o manuseio, higiene e conservação da carne são os fatores que mais reprovam o produto brasileiro. Já nos fatores éticos o Brasil leva certa desvantagem sobre a concorrência pelo histórico com mão-de-obra escrava e o desmatamento de florestas para a criação do gado (principalmente a Floresta Amazônica) (SOUZA, 2008).

Nas operações comerciais brasileiras, algumas peculiaridades podem ser evidenciadas. A União Européia não permite, por exemplo, a entrada da "carne 
bovina com osso" ou "bovinos vivos" em seu território, por considerar o território brasileiro incerto quanto à incidência da febre aftosa. Já os Estados Unidos criam barreiras para a importação de "carne fresca" do Brasil pelos mesmos motivos que a União Européia. Apenas a carne bovina industrializada não sofre proibições para ingressar no mercado norte-americano, desde que a fábrica tenha sido visitada pelo agente de inspeção norte-americano a fim de certificá-la posteriormente. Além disso, o Ministério da Agricultura brasileiro deve emitir um certificado sanitário para cada lote de carne bovina industrializada exportada (IPEA,2001) (ABREU; HERRRA; e TEIXEIRA, 2006, p. 14). consequências nos âmbitos econômico, social e político, este fenômeno tornou-se um assunto amplamente discutido e conhecido. Paula, et al (2011), reiteram que a inflação é um fenômeno que esteve presente ao longo da constituição da economia brasileira, sendo definido, de modo mais simples, como um aumento no nível geral de preços da economia. Lopes e Rossetti (2005), de maneira mais rigorosa descrevem a inflação como um fenômeno macroeconômico, dinâmico e de natureza monetária, caracterizado por uma elevação apreciável e persistente do nível geral de preços de todos os fatores e produtos da economia.

O fenômeno inflacionário aparece em sua faculdade de se generalizar. Por se espalhar, como metástase pelo organismo econômico. Todos os preços são afligidos por se intercomunicarem uns com os outros. Se o preço do aço se eleva, há uma propagação para todas as mercadorias que utilizam este bem intermediário em sua produção. A chapa de aço aumenta de preço na ponta da siderurgia, corre se propagar até o preço da lavadora de roupa, da geladeira, do automóvel, do caminhão, do ônibus, do trator, do garfo, da tesoura, do fogão, da faca... como numa cadeia de interligações em vários sentidos. Os preços desses produtos industriais 
tendem a crescer na proporção do peso que o bem intermediário ocupa na produção. (SILVEIRA FILHO, 2010, p. 68).

Conforme Lopes e Rossetti (2005) e Silveira Filho (2010), na literatura econômica tradicional, as causas predominantes ou mais comuns da elevação do nível geral de preços são duas: (1) o excesso de demanda agregada em relação à oferta agregada, que provoca a inflação de demanda; e (2) a elevação dos custos componentes da oferta agregada, que provoca a inflação de custos ou inflação de oferta.

Além desses dois tipos puros de inflação, podem ainda ocorrer inflações mistas, impulsionadas tanto por excesso de demanda quanto por custos em expansão. Finalmente, há ainda outras teorias não alinhadas com as exposições convencionais da demanda e dos custos. Entre estas, destacam-se as teorias estruturalistas da inflação, segundo as quais as pressões inflacionárias resultam de causas estruturais, geralmente relacionadas com os estados de subdesenvolvimento econômico ou com desequilíbrios associados ao crescimento acelerado. E, mais recentemente, a abordagem inercialista, que explica a inflação a partir de forças de realimentação (de que é exemplo a indexação generalizada da economia) e de expectativas dos agentes econômicos quanto ao comportamento ascensional dos preços. Pelas expectativas de alta e pelos mecanismos de realimentação, estabelecem-se, segundo esta abordagem, forças inercias que reproduzem automaticamente a inflação passada no presente. (LOPES \& ROSSETTI, 2005, p. 315).

Quadro 1: Inflação e poder aquisitivo

\begin{tabular}{|r|c|c|c|c|c|c|c|}
\hline Ano & $\begin{array}{c}\text { Sal Nom } \\
\mathbf{\$}\end{array}$ & $\begin{array}{c}\text { Preço } \\
\mathbf{\$}\end{array}$ & $\begin{array}{c}\text { Inflação } \\
\mathbf{\%}\end{array}$ & $\begin{array}{c}\text { Qtd } \\
\mathbf{K g}\end{array}$ & $\begin{array}{c}\text { Sal Real } \\
\mathbf{\$}\end{array}$ & $\begin{array}{c}\text { Perda } \\
\text { Real \% }\end{array}$ & NI \\
\hline 0 & $1.000,00$ & 2,00 & 0,00 & 500,00 & $1.000,00$ & 0,00 & 100,00 \\
\hline 1 & $1.000,00$ & 2,50 & 25,00 & 400,00 & 800,00 & $-20,00$ & 80,00 \\
\hline 2 & $1.000,00$ & 3,50 & 40,00 & 285,71 & 571,43 & $-42,86$ & 57,14 \\
\hline 3 & $1.000,00$ & 5,25 & 50,00 & 190,48 & 380,95 & $-61,90$ & 38,10 \\
\hline 4 & $2.625,00$ & 5,25 & 0,00 & 50,00 & $1.000,00$ & 0,00 & 100,00 \\
\hline
\end{tabular}

Fonte: SILVEIRA FILHO, 2010, P. 69.

*NI: números índices

O quadro acima mostra uma situação em números do processo inflacionário de uma economia. Como mostra o autor Silveira Filho, 2010, p. 69:

Todo o salário nominal de $\$ 1.000,00$ é convertido em farinha de trigo, cujo preço por quilo é de $\$ 2,00$. No ano zero, o salário nominal compra 500 quilos de farinha de trigo. Este é o marco de seu poder aquisitivo. Do ano 1 até o ano 3, a inflação se manifesta. O salário nominal permanece sempre igual. Em contrapartida, a quantidade de farinha de trigo convertida cai sistematicamente a cada ano da mesma forma que o salário real. No passar da régua, o salário real perdeu $61,90 \%$ de seu poder aquisitivo inicial, valendo apenas $\$ 380,95$ e comprando somente 190,48 quilos de farinha de trigo. No ano 4 , o salário nominal é reajustado para restaurar seu poder de compra perdido. Voltou a adquirir os mesmos 500 quilos de farinha ao mesmo valor real antigo de $\$ 1.000,00$. [...]. O fluxo de consumo/produção, produção/consumo se restabelece e ganha solução de continuidade pelo menos para permanecer idêntico ao que era. É o mínimo aceitável para evitar o colapso do sistema.

21 Segundo Paula, et al (2011), a inflação provocou estragos de tamanha ordem na economia brasileira e a cada período os economistas atribuíam um diagnóstico como causa para o 
aumento generalizado do nível de preços, e os planos de estabilização que surgiam, seguiam tais explicações deste fenômeno.

Para Silveira Filho (2010), os anos do período de 1974 a 1994 foram tenebrosos e difíceis para a economia brasileira, e até a implementação do Plano Real em 1994 a estabilização da economia passou a ser a principal meta dos governos. Neste intervalo existiram sete programas de estabilização que podem ser definidos como uma coleção de fracassos, são eles: Plano Cruzado I, Plano Cruzado II, Plano Bresser, Plano Feijão com Arroz, Plano Verão, Plano Collor I e Plano Collor II.

Tabela 1: Brasil: a inflação no período 1980-2003. Taxas de variação anual dos preços.

\begin{tabular}{c|c|c|c}
\hline Anos & $\begin{array}{c}\text { Variação anual dos preços } \\
(\%)\end{array}$ & Anos & Variação anual dos preços (\%) \\
\hline 1980 & 110,2 & 1992 & $1.157,9$ \\
1981 & 95,2 & 1993 & $2.708,6$ \\
1982 & 99,7 & 1994 & $1.093,8$ \\
1983 & 211,0 & 1995 & 14,8 \\
1984 & 223,8 & 1996 & 9,3 \\
1985 & 231,5 & 1997 & 7,5 \\
1986 & 65,0 & 1998 & 9,7 \\
1987 & 415,8 & 1999 & 19,9 \\
1988 & $1.037,6$ & 2000 & 9,8 \\
1989 & $1.782,9$ & 2001 & 10,4 \\
1990 & $1.476,6$ & 2002 & 26,4 \\
1991 & 480,2 & 2003 & 7,7 \\
\hline
\end{tabular}

Fonte: Lopes \& Rossetti, 2005, p. 354.

De acordo com Lopes e Rossetti (2005), três meses após a decretação da primeira tentativa, o Plano Cruzado, a inflação reduziu temporariamente chegando a níveis próximos de zero devido ao congelamento generalizado de preços, no entanto os preços efetivamente praticados passaram a incorporar ágios em função do desajuste entre uma oferta rígida e uma demanda em expansão, sinalizando a existência de uma inflação reprimida, que era alimentada por uma expansão na oferta de moedas e pela elevação dos níveis de emprego e de salário, fazendo com que a inflação voltasse a crescer e chagasse a patamares mais elevados que o observado antes da adoção do plano.

A estabilidade de preços foi conquistada com o Plano Real. Mas este sucesso não pode ser atribuído apenas às medidas do Governo Itamar e/ou FHC. Deve-se salientar a importância da abertura econômica imposta pelo Governo Collor em 1990. [...]. Se por um lado isso foi feito de maneira violenta e sem contrapartida dos parceiros comerciais brasileiros, por outro, possibilitou o sucesso do Plano Real quatro anos mais tarde. A abertura econômica possibilitou acumular reservas e deu uma folga cambial, que, juntamente com o aumento dos bens importados, contribuíram para neutralizar a inflação. (PAULA, et al. 2011, p. 75-76). a criação da nova moeda, o real, foi a mais bem sucedida política de estabilização monetária entre todas as praticadas anteriormente, visto que se fundamentou na bem 
sucedida estratégia de um regime bi monetário por um tempo determinado, dado que antes do real os indexadores foram unificados em um único índice, a URV - Unidade Real de Valor, que durante um tempo programado exerceu a função de unidade de conta e posteriormente com a assimilação dos valores expressos neste índice, foi substituído pelo novo padrão monetário, e assim, o plano conseguiu num primeiro momento controlar o componente de demanda e posteriormente eliminar o componente inercial da hiperinflação observada.

\section{Procedimentos metodológicos}

A escolha do recorte temporal e geográfico ratifica-se pelo papel apresentado pelo Brasil na década de 2000, o qual consolidou-se como grande produtor e exportador de carne bovina do mundo (ABIEC, 2016).

Para encontrar os valores, preço unitário em dólar, valor em reais, preço unitário em reais, foram utilizadas as respectivas fórmulas:

Preço unitário em dólar: $\mathrm{Q}_{\mathrm{x}} / \mathrm{V}_{\mathrm{d}}$

Valor em reais: $\mathrm{V}_{\mathrm{d}}{ }^{*} \mathrm{TC}$

Preço unitário em reais: $\mathrm{Q}_{\mathrm{x}} / \mathrm{V}_{\mathrm{r}}$

Logo,

$\mathrm{Q}_{\mathrm{x}}=$ Quantidade Exportada

$\mathrm{V}_{\mathrm{d}}=$ Valor em dólar

$\mathrm{V}_{\mathrm{r}}=$ Valor em reais

4 TC (U.M.C/US\$) = Taxa de Câmbio

Para tanto, foi feita uma revisão literária sobre a pecuária e sobre a inflação no Brasil. A inflação brasileira foi utilizada como uma variável proxy para verificar o comportamento das exportações de carne bovina, ao longo da série histórica, quando o nível de preços interno sofre variações. A metodologia utilizada na pesquisa foi a análise exploratória, sendo utilizado dados secundários do AliceWeb, IPEADATA e Banco Central do Brasil.

\section{Relação entre inflação, preço unitário e a exportação da commodity carne bovina}

Apesar da agropecuária não se apresentar mais como centro dinâmico da economia brasileira, a mesma, ainda assim, é essencial para o desenvolvimento de um país. A pecuária no Brasil, onde possui condições favoráveis para seu desempenho, contribui significativamente para a geração de reservas internacionais para fazer frente a compra de insumos e bens de capital para a manutenção das atividades econômicas (BRASIL, 2014).

37 A bovinocultura, segundo o Ministério da Agricultura, Pecuária e Abastecimento (BRASIL, 2014. p. 7), apresenta-se como "[...] um dos setores mais importantes do agronegócio brasileiro e consequentemente da economia nacional. O Brasil possui o maior rebanho comercial do mundo, é o maior exportador de carne bovina, segundo maior produtor de carne e sexto maior produtor de leite". 
Segundo Mustefaga $(2014$, p. 1) a carne é um item que, "[...] dentro do grupo de Alimentação e Bebidas do IPCA, é composto pelas carnes bovina, suína e ovina. Mas, as carnes bovinas são o principal componente, uma vez que representam cerca de $90 \%$ no peso de sua composição [...]". Por esse motivo, esta análise se concentrará na relação entre a exportação de carne bovina e a inflação com uma pequena apreciação do preço unitário da carne bovina de 2000 a 2015.

\section{1. Correlação entre a quantidade exportada e a inflação (IPCA)}

De acordo com a Tabela 2, que mostra a variação da quantidade de carne bovina exportada e a do Índice de Preços ao Consumidor Amplo do ano de 2000 a 2015 no Brasil, indica que, em praticamente todos os anos, a medida que aumenta o índice de preços a quantidade exportada decresce, e vice-e-versa.

Tabela 2: Quantidade exportada de carne bovina (Qtd. X) e IPCA do ano de 2000 a 2015 - Brasil

\begin{tabular}{ccccr}
\hline Ano & Qtd. X & $\boldsymbol{\Delta} \%$ & IPCA & \multicolumn{1}{c}{$\boldsymbol{~ \%}$} \\
\hline 2000 & 190.214 .477 & & 5,97 & \\
2001 & 369.845 .180 & 94,44 & 7,67 & 28,43 \\
2002 & 433.192 .791 & 17,13 & 12,53 & 63,29 \\
2003 & 623.587 .812 & 43,95 & 9,30 & $-25,78$ \\
2004 & 929.599 .556 & 49,07 & 7,60 & $-18,29$ \\
2005 & 1.088 .727 .231 & 17,12 & 5,69 & $-25,14$ \\
2006 & 1.228 .195 .093 & 12,81 & 3,14 & $-44,78$ \\
2007 & 1.293 .396 .586 & 5,31 & 4,46 & 41,90 \\
2008 & 1.028 .455 .879 & $-20,48$ & 5,90 & 32,42 \\
2009 & 929.829 .577 & $-9,59$ & 4,31 & $-26,95$ \\
2010 & 952.947 .162 & 2,49 & 5,91 & 37,04 \\
2011 & 823.452 .362 & $-13,59$ & 6,50 & 10,06 \\
2012 & 949.073 .033 & 15,26 & 5,84 & $-10,22$ \\
2013 & 1.188 .276 .136 & 25,20 & 5,91 & 1,23 \\
2014 & 1.231 .140 .849 & 3,61 & 6,41 & 8,40 \\
2015 & 1.082 .151 .592 & $-12,10$ & 10,67 & 66,57 \\
\hline
\end{tabular}

FONTE: Elaboração própria, a partir dos dados de Aliceweb, IPEADATA e Banco Central do Brasil.

de 2002 a 2003 (Tabela 2) a quantidade exportada de carne bovina no Brasi aumentou $43,95 \%$ devido a uma significativa queda (negativa) do nível de preços, neste mesmo período, de $25,78 \%$, embora a inflação tenha atingido 9,3 pontos percentuais em 2003. Além da queda significativa da inflação o aumento das exportações de carne foi induzido, também, pela desvalorização do real frente ao dólar em 2,93 em 2002 e 3,07 em 2003 (BACEN, 2016).

41 Na situação contrária, pode-se observar o resultado apresentado do ano de 2007 a 2008 em que a inflação subiu 32,42\%, e a exportação de carne bovina, em contrapartida, recuo expressivamente em $20,48 \%$. Apesar de a inflação ter subido substancialmente, a taxa de 
câmbio se manteve abaixo de $R$ \$2,00 (BACEN, 2016), o que significa uma valorização do real, e consequentemente aumento da concorrência no mercado interno.

Vale destacar também os resultados apresentados do ano de 2011/2012 e 2012/2013, os quais foram semelhantes ao primeiro caso (2002 a 2003), em que a inflação apresentou queda de $10,22 \%$ e baixo crescimento de $1,23 \%$, respectivamente, e a quantidade de carne bovina exportada aumentou $15,26 \%$ e $25,20 \%$, respectivamente.

Do ano de 2014 a 2015, o aumento da inflação em 66,57\% induziu a uma redução de 12,10\% da quantidade de carne bovina enviada ao exterior, visto que para o produtor é mais vantajoso direcionar sua produção para o mercado interno, já que segundo Paula, et al (2011), a inflação é tida como um aumento no nível geral de preços da economia. As oscilações das exportações conforme a BRASIL (2014), é devida ao

O consumo de carne bovina está crescendo bastante no Brasil e no mundo, muito devido ao aumento da renda da população. As projeções são deque no Brasil o consumo cresça a uma taxa de 3,6\% a.a., acumulando no final de um período de 10 anos, um aumento de $42,8 \%$. A demanda mundial também está em expansão e as exportações devem aumentar cerca de $2,5 \%$ a.a. [...] a confirmação dessas taxas, em 10 anos haverá uma demanda de carne bovina superior à oferta, o que poderá gerar desequilíbrio para o setor, podendo resultar em aumento de preço e inflação (BRASIL, 2014. p. 8).

Os resultados anteriormente apresentados podem ser facilmente visualizados no Gráfico 1, que mostra a correlação entre a quantidade exportada (em Kg líquido) e o Índice de Preço ao Consumidor Amplo (IPCA) de 2000 a 2015 na economia brasileira.

Gráfico 1: Correlação entre a quantidade exportada (em Kg líquido) e o Índice de Preço ao Consumidor Amplo (IPCA) de 2000 a 2015 - Brasil

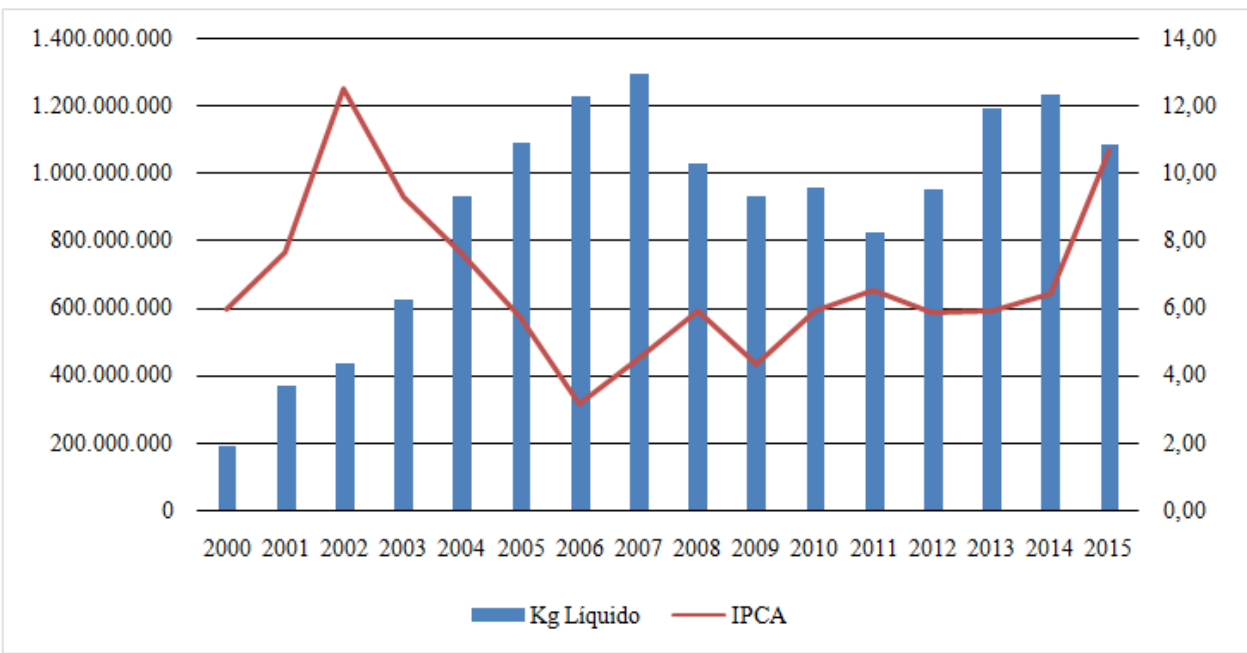

Fonte: Fonte: ELABORAÇÃo PRóPRIA, A PARTIR dos DAdOS DE ALICEWEB, IPEADATA E BANCO CENTRAL DO BRASIL.

Os resultados apresentados anteriormente por ser um índice geral, requer levar em consideração a correlação também entre a quantidade exportada e o preço unitário. Assim, ver-se-á a necessidade desta relação com preço específico do produto no período em estudo. 


\section{2. Correlação entre a quantidade exportada e o preço unitário da carne bovina}

O preço unitário da carne bovina apresentou a mesma tendência da dinâmica apresentada pelo IPCA, de acordo com a Tabela 3, que apresenta a variação da quantidade exportada e a do preço unitário de 2000 a 2015.

Tabela 3: Correlação entre a quantidade exportada e o preço unitário de 2000 a 2015 e variação percentual - Brasil

\begin{tabular}{c|c|c|c|c}
\hline Ano & Qtd. X & $\boldsymbol{\Delta} \%$ & $\begin{array}{c}\text { Preço } \\
\text { unitário/RS }\end{array}$ & $\boldsymbol{\Delta} \%$ \\
\hline 2000 & 190.214 .477 & - & 4,88 & - \\
2001 & 369.845 .180 & 94,44 & 4,72 & $-3,24$ \\
2002 & 433.192 .791 & 17,13 & 5,29 & 12,04 \\
2003 & 623.587 .812 & 43,95 & 5,72 & 8,10 \\
2004 & 929.599 .556 & 49,07 & 6,21 & 8,54 \\
2005 & 1.088 .727 .231 & 17,12 & 5,42 & $-12,61$ \\
2006 & 1.228 .195 .093 & 12,81 & 5,57 & 2,72 \\
2007 & 1.293 .396 .586 & 5,31 & 5,33 & $-4,33$ \\
2008 & 1.028 .455 .879 & $-20,48$ & 7,23 & 35,74 \\
2009 & 929.829 .577 & $-9,59$ & 6,53 & $-9,75$ \\
2010 & 952.947 .162 & 2,49 & 7,15 & 9,44 \\
2011 & 823.452 .362 & $-13,59$ & 8,53 & 19,31 \\
2012 & 949.073 .033 & 15,26 & 9,31 & 9,20 \\
2013 & 1.188 .276 .136 & 25,20 & 9,79 & 5,16 \\
2014 & 1.231 .140 .849 & 3,61 & 11,13 & 13,63 \\
2015 & 1.082 .151 .592 & $-12,10$ & 14,45 & 29,90 \\
\hline
\end{tabular}

Fonte: ELABOrAção PRóPRIA, A PARTIR dos dADOS DE ALICEWEB, IPEADATA E BANCO CENTRAL do BRASIL.

Observando estas variações ano após ano, vê-se que, embora o peço da carne tenha aumentado $12 \%$ de 2000 para 2001 a quantidade exportada aumenta significativamente em 94\%. Outros anos que apresentaram resultados expressivos foram, 2002/2003, 2003/2004 e 2012/2013 que cresceram, nestes intervalos, em aproximadamente, 44\%, 49\% e $25 \%$, respectivamente, à medida que os preços se mantiveram quase inalterados, ou seja, com baixo crescimento, aproximadamente, de $8 \%, 9 \%$ e $5 \%$, respectivamente. Segundo, ABREU; HERRA; e TEIXEIRA (2006),

[...] Nos últimos anos, poucos países tiveram um crescimento no comércio internacional do agronegócio quanto o Brasil, sendo um dos líderes mundiais na produção e exportação de vários produtos agropecuários, tais como café, açúcar, álcool e sucos de frutas. Dentre os vários setores que se destacam, o de carne bovina é um deles. No ano de 2004 o Brasil alcançou a meta de maior exportador mundial de carne (ABREU; HERRA; e TEIXEIRA, 2006. p. 2).

De 2007/2008 e 2014/2015 a quantidade exportada da carne bovina apresentou uma drástica queda de $20,48 \%$ e $12,10 \%$, respectivamente, ao mesmo tempo em que o preço 
unitário aumentou expressivamente em $35,74 \%$ e 39,90\%, respectivamente, mesmo com a “[...]integração do maior exportador de carne bovina, Brasil, e do segundo maior importador, Rússia, que contaram em 2008 com uma intersecção de transações em torno de 60\%" (THOMÉ et al, 2010. p. 14). Segundo, ABREU; HERRA; e TEIXEIRA (2006), uns dos fatores as restrições as exportações, brasileiras, estão intimamente ligadas as barreiras colocadas pelos países europeus, que “[...] vão desde a questão sanitária (principalmente em função da febre aftosa) a questões éticas e sociais (mão-de-obra escrava, desmatamento da floresta Amazônica para a formação de pastos) " (ABREU; HERRA; e TEIXEIRA, 2006. p. 2).

Os resultados anteriormente apresentados (Tabela 2) podem ser facilmente percebidos no Gráfico 2, que mostra a correlação entre a quantidade exportada (em Kg líquido) e o preço unitário de 2000 a 2015 na economia brasileira.

Gráfico 2: Correlação entre a quantidade exportada (em Kg líquido) e o preço unitário da carne nos anos de 2000 a 2015 - Brasil

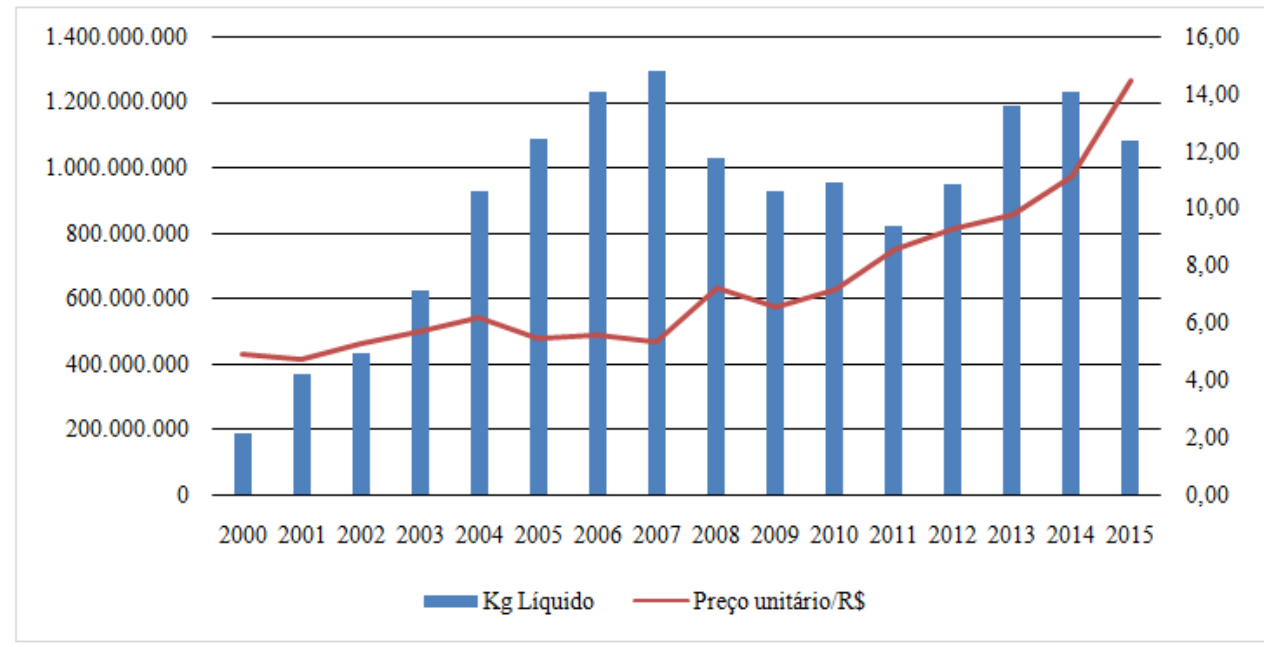

Fonte: elaboraçÃo PRópria, A PARTIR dos dAdOS DE ALICEWEB, IPEADATA E BANCO CENTRAL do BRASIL.

Com a elevação da inflação os produtores de carne acharam mais vantajoso direcionar sua produção para o mercado interno em vez do externo, devido a elevada procura, até mesmo porque a pecuária ocupa $80 \%$ de sua produção para o mercado interno, mesmo com o expressivo aumento das exportações nos últimos anos (SABADIN, 2006).

\section{Considerações finais}

51 Ao longo do trabalho exposto pode-se perceber a importância da agropecuária para a economia nacional, é um setor que se destaca e promove emprego e renda. Diante da importância do comércio da carne bovina, se objetivou fazer um estudo sobre a correlação entre a exportação do produto e a inflação brasileira nos anos de 2000 a 2015, para ver se as variações nos preços afetariam as exportações no setor e como afetariam.

52 Então a partir da série histórica da economia agroexportadora, ou melhor, da exportação da carne bovina, pôde-se fazer uma análise da conjuntura desta última juntamente com as variáveis: índice geral de preços (IPCA) e os níveis de preços unitários. Nesse contexto, 
constatou-se que durante o período em estudo, existe um comportamento antagônico da inflação e do nível de preços unitários em relação à exportação de carne bovina.

À medida que os níveis de preços internos aumentam o produtor ver mais vantagens em concentrar suas vendas no Brasil. Já que se despenderiam de menos custos e trabalho para vender sua mercadoria internamente, passando a investir mais no mercado nacional e consequentemente diminuindo as exportações. Sendo assim, há uma relação inversa entre a inflação brasileira e a quantidade de carne bovina que é exportada.

\section{BIBLIOGRAFIA}

ABIEC. Associação Brasileira das Indústrias Exportadoras de Carne. Estatísticas. Disponível em: < http://www.abiec.com.br/download/stat_mercadomundial.pdf >. Acesso em: 22 de abril de 2016. ABREU, A.; HERRRA, V. E.; TEIXEIRA, M. A. Mercado mundial de carne bovina: participação brasileira e barreiras às exportações. In: CONGRESSO DA SOCIEDADE BRASILEIRA DE ECONOMIA E SOCIOLOGIA RURAL, 44. 2006, Fortaleza. Anais... Fortaleza: SOBER, 2006.

ALY JUNIOR, O. RAMOS, P. Boi Verde: o Brasil e o comércio internacional de carne bovina. 2006.

BACEN. Taxa de câmbio Livre - Dólar americano (venda) Média de período anual. Consulta séries. Disponível em: < http://www.bcb.gov.br/pt-br/\#!/n/SERIESTEMPORAIS>. Acesso em: 01 de abril de 2016.

BRASIL. Ministério da Agricultura, Pecuária e Abastecimento. Cadeia produtiva da carne bovina / Ministério da Agricultura, Pecuária e Abastecimento, Secretaria de Política Agrícola, Instituto Interamericano de Cooperação para a Agricultura; Brasília: IICA: MAPA/SPA, 2007. (Agronegócios; v. 8).

BRASIL. Ministério da Agricultura, Pecuária e Abastecimento. Plano mais pecuária / Ministério da Agricultura, Pecuária e Abastecimento. $1^{a}$ edição. Assessoria de Gestão Estratégica. - Brasília: MAPA/ACS, 32 p. 2014.

FURTADO, C. Formação Econômica do Brasil. Companhia Editora Nacional. 32 Edição. 2005.

ISAAC, L. F. As Exportações de Carne Bovina do Brasil e a Taxa de Câmbio. 2006.

LOPES, J. C. ROSSETTI, J. Pl. Economia monetária. 9. ed. rev. ampl. e atual. - São Paulo: Atlas, 2005. MUSTEFAGA, P. S. Impactos dos preços da carne bovina para a inflação medida pelo IPCA. In: Nota Técnica/CNA Brasil. Outubro de 2014.

PAULA, D.; SOUZA. G. F.; FERNANDES, M. M.; FALCO, G. P. A inflação na economia brasileira. Revista Vianna Sapiens, v. Vol.2, p. 54-90, 2011.

SABADIN, C.; Michels, Ido. O Comércio Internacional da Carne Bovina e a Indústria Frigorífica Exportadora. 2006.

SARTIN, K. R.; JOHANN, A. R. G.; SOUZA, C. B.; NASCIMENTO, A. R.; SILVEIRA, M. A. Análise de Correlação e Regressão das Exportações de Carne Bovina e de Frango Brasileira. In: Conjuntura Econômica Goiana № 34. Setembro, 2015. 
SILVEIRA FILHO, J. da. A inflação no Brasil: os anos tenebrosos de 1974 a 1994. Edição 14, volume 8, número 1, janeiro/junho, 2010.

SOUZA, F. P. O Mercado da Carne Bovina no Brasil. Rev. Acad., Ciênc. Agrár. Ambient., Curitiba, v. 6, n. 3, p. 427-434, jul./set. 2008.

THOMÉ, K. M.; CARVALHO, J. M.; CALEGARIO, C. L.; LEITÃO, F. O.; BEASLEY, C. M. G. Comércio internacional de carne bovina: características institucionais que envolvem Brasil e Rússia. Informe Gepec (Impresso), v. 15, p. 99-111, 2011.

\section{RESUMOS}

A pecuária figura-se desde o início da colonização brasileira até a contemporaneidade como uma atividade econômica muito importante para o desenvolvimento nacional. Tendo em vista sua expansão - após a abertura comercial brasileira na década de 1990, bem como com as sucessivas quedas nas taxas de inflação no decorrer da mesma década, - seu dinamismo e sua relevância como um dos principais setores geradores de emprego e renda no território nacional, este trabalho tem como objetivo analisar a correlação existente entre as exportações brasileiras de carne bovina e o nível de preços relativos internos no período de 2000 a 2015 . Através de pesquisa descritiva-exploratória e por meio de variáveis secundárias do banco de dados do AliceWeb, do IPEADATA e do Banco Central do Brasil, foi possível observar que existe uma relação inversamente proporcional entre as exportações de carne bovina do País e seu nível relativo de preços durante a série temporal estudada.

Livestock figure since the beginning of Brazilian colonization to the contemporary world as a very important economic activity for national development. In view of its expansion - after the Brazilian trade liberalization in the 1990s, as well as the successive declines in inflation rates during the same decade - its dynamism and its relevance as one of the main sectors that generate employment and income in the territory national, this work aims to analyze the correlation between Brazilian beef exports and the level of domestic relative prices from 2000 to 2015 . through descriptive and exploratory research and through secondary variables AliceWeb database, the IPEADATA and the Central Bank of Brazil, it was observed that there is an inverse relationship between beef exports of the country and its relative price level during the time series studied.

Chiffre d'élevage depuis le début de la colonisation du Brésil au monde contemporain comme une activité économique très importante pour le développement national. Compte tenu de son expansion - après la libéralisation brésilienne du commerce dans les années 1990, ainsi que les baisses successives des taux d'inflation au cours de la même décennie - son dynamisme et sa pertinence en tant que l'un des principaux secteurs qui génèrent des emplois et des revenus sur le territoire national, ce travail vise à analyser la corrélation entre les exportations de bœuf brésilien et le niveau des prix intérieurs relatifs de 2000 à 2015. grâce à la recherche descriptive et exploratoire et à travers la base de données secondaire AliceWeb variables, le IPEADATA et la Banque centrale du Brésil, il a été observé qu'il existe une relation inverse entre les exportations de bœuf du pays et son niveau de prix par rapport au cours de la série de temps étudiée.

La actividad pecuaria desde el inicio de la colonización hasta hoy ha sido una actividad económica muy importante para el desarrollo del país. Teniendo en cuenta su expansión posterior a la apertura comercial brasilera en la década de 1990, así como las sucesivas caídas de las tasas de la inflación en el transcurso del mismo período, su dinamismo y relevancia como uno de los principales sectores generadores de empleo e ingresos para la nación. Este trabajo tiene 
como objetivo analizar la correlación existente entre las exportaciones de carne bovina y el nivel de precios internos en el periodo de 2000 a 2015. La investigación, que es de tipo descriptivo exploratorio y aborda las variables secundarias del banco de datos de AliceWeb, do IPEADATA e do Banco Central do Brasil, permite observar que existe una relación inversamente proporcional entre las exportaciones de carne bovina y su nivel relativo de precios durante el periodo estudiado.

ÍNDICE

Palavras-chave: Exportação, pecuária, inflação.

Palabras claves: exportación pecuaria, inflación.

Keywords: Export, livestock, inflation.

Mots-clés: Export, bétail, l'inflation.

\section{AUTORES}

\section{DENIS FERNANDES ALVES}

Mestrando em Economia pelo Programa de Pós-Graduação em Economia da Universidade Federal do Rio Grande do Norte (PPECO/UFRN). E-mail: denis_fernandes@outlook.com

\section{PEDRO JOSÉ REBOUÇAS FILHO}

Mestre em Economia do Setor Público pela Universidade Federal do Ceará (UFC). Pesquisador do GETEDRU. Professor do Departamento de Economia da Universidade Regional do Cariri (URCA). E-mail: preboucas81@hotmail.com

\section{PAULO VICTOR MACIEL DA COSTA}

Graduando em Ciências Econômicas pela Universidade Regional do Cariri (URCA). Pesquisador do Observatório das Migrações no Estado do Ceará aprovado no CNPq (2013/2017). Estagiário do Serviço de Apoio às Micro e Pequenas Empresas (SEBRAE). Email: paulovictorma22@hotmail.com 